\title{
Are graduate students receiving adequate education and training in fluency disorders?
}

\author{
Nina Santus', Glen Tellis', Fanhui Kong ${ }^{3}$ \\ 'University of Georgia, Communication Sciences and Disorders, GA; ${ }^{2}$ Misericordia University, Department of Speech-Language Pathology, PA; \\ ${ }^{3}$ Department of Mathematics and Computer Science, Wilkes University, PA, USA
}

\begin{abstract}
Purpose: The purpose of this study was to determine the fluency education needs and perceptions of speech-language pathology students attending American Speech-Language and Hearing Association (ASHA) accredited programs at universities in the United States. Previous studies have shown that practicing speech-language pathologists lack knowledge pertaining specifically to assessment and treatment of fluency disorders. We were interested in determining what information students were learning with regard to fluency disorders, and the amount of clinical exposure that students received during their college careers.
\end{abstract}

Methods: A 70-question survey was sent to 258 professors who teach fluency disorders courses in accredited Communication Sciences and Disorders (CSD) programs. The professors were asked to forward the survey to their students. Data from 766 responding students from 102 different universities were collected.

Results: Results indicated that as speech-language pathology students advance through their education, their knowledge and comfort levels increase when assessing and treating fluency disorders. Graduate students, however, reported not having adequate knowledge with regard to administering assessment tests or differentiating between various types of treatment.

Conclusions: Systematic training in specific aspects of assessment and treatment of fluency disorders, along with the restructuring of fluency disorders coursework is needed. Increased exposure to fluency disorders continues to be needed for speech-language pathology students at the university level to successfully serve this population.

Keywords: Fluency disorders, Assessment, Treatment, Speech-language-pathology

\section{INTRODUCTION}

In the United States, coursework and training in fluency disorders is distributed throughout the graduate and undergraduate curriculum for those in Communication Sciences and Disorders (CSD) programs. A recent survey by Yaruss et al. [1] however, found that CSD programs in the United States reported minimal education and required coursework in fluency disorders at the undergraduate level, though there is increased required coursework in this area at the graduate level. Yaruss and colleagues [1] reported that faculty members who taught courses in fluency disorders did not have extensive clinical experience in this area of specialty. Sommers and Caruso [2] conducted a survey of university clinical directors who rated fluency and voice disorders as the highest priority in terms of training needs. Another area of concern was that master's

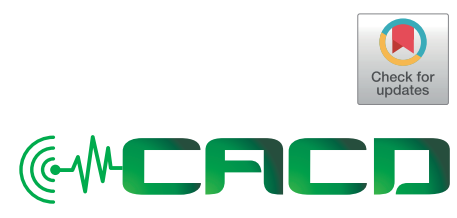

Received: September 13, 2019 Revision: December 16, 2019 Accepted: December 24, 2019

\section{Correspondence:}

Nina Santus

University of Georgia, Communication Sciences and Disorders, 547 Aderhold Hall, Athens, Georgia 30602, USA Tel: +706-542-6355

Fax: +706-542-5348

E-mail: nmsantus@gmail.com

(C) 2019 The Korean Association of SpeechLanguage Pathologists

This is an Open Access article distributed under the terms of the Creative Commons Attribution NonCommercial License (http://creativecommons.org/ licenses/by-nc/4.0/) which permits unrestricted noncommercial use, distribution, and reproduction in any medium, provided the original work is properly cited. 
students received less clinical hours in fluency and voice disorders than language, articulation, and phonology disorders. Although language, articulation, and phonological disorders are more prevalent, students are still expected and required by the American Speech-Language Hearing Association (ASHA) to have adequate knowledge in assessing and treating fluency and voice disorders as they fall under the speech-language pathology scope of practice. The issue of a lack of clinical hours in this area was echoed by Brisk, Healey, and Hux [3] who observed that academic and clinical training in fluency disorders has been lacking for approximately 30 years.

In a nationwide survey of 255 speech-language pathologists, Tellis, Bressler, and Emerick [4] found that the majority had completed coursework in fluency disorders; however, less than half took a full semester of fluency coursework, and a minimal number only had either a few lectures of undergraduate coursework or lacked fluency coursework altogether. In the Tellis et al. [4] study, $37.3 \%$ of respondents were unable to accurately identify onset characteristics of stuttering, and $78.2 \%$ had never heard of response contingent methods (e.g., Lidcombe) to treat stuttering. Many of the participants indicated that they knew how to teach stuttering modification techniques; however, $60.0 \%$ of respondents indicated that they did not know how to teach cancellations, $51.2 \%$ did not know how to teach pull-outs, and $68.5 \%$ did not know how to teach preparatory sets. These results demonstrate that 20 years after the Brisk et al. [3] study, both speech-language pathology students and practicing clinicians, are struggling to retain and demonstrate adequate assessment and treatment knowledge pertaining to fluency disorders.

Because of the concern relating to the lack of experience in fluency disorders, Yaruss et al. [1] surveyed 191 university CSD programs in the United States. A majority (85.8\%) of the responding programs reported having a required graduate level course in fluency disorders, with fewer programs allowing students to graduate without taking a course in fluency disorders than in past years. About half (52.3\%) of the programs required assessment of fluency disorders in their clinical practicum, and even fewer programs required experience in the treatment of fluency disorders during their clinical experience. Students from only $13.8 \%$ of the responding programs were credited with fluency disorders hours when treating other conditions such as motor speech, reading, articulation disorders, and non-fluent aphasia. An even greater cause for concern was that $42.3 \%$ of students graduated without any clinical hours in fluency disorders. These results from Yaruss et al. [1] revealed that many faculty and supervisors have less experience working with people who have fluency disorders. The authors indicated that future students may have inadequate exposure to Board Certified Specialists in Fluency Disorders (BCS-F) and experts.

With limited training and education in fluency disorders at the university level, it is possible that practicing clinicians who demonstrate partial knowledge about fluency disorders may lose the trust of their clients [7]. Speech-language pathologists who work in schools also have reported feelings of inadequacy when treating fluency disorders [1,6-9]. It is quite possible that these professionals lack confidence in assessing and treating fluency disorders because they did not receive sufficient fluency education or opportunities to assess and treat fluency disorders as part of their college education. This lack of fluency training for speech-language pathologists may also result in persons with fluency disorders being negatively stereotyped by speech-language pathologists or students who are completing degrees in Communication Sciences and Disorders [10-17]. According to Cooper and Cooper [11] some speech-language pathologists hold negative stereotypes towards the personality traits of persons with fluency disorders. The authors believed that it was imperative that continuing education in fluency disorders be offered to speech-language pathologists, to expose them to the latest information about fluency disorders to minimize those negative stereotypes.

A review of the literature indicates that a majority of practicing speech-language pathologists, primarily in the school setting, have insufficient knowledge and exposure related to assessing and treating persons with fluency disorders. It is possible that this lack of knowledge stems from a deficient educational foundation at the university level. Yaruss et al. [1] surveyed department chairs and faculty members with expertise in fluency disorders; however, we wanted to find out from the students themselves about the level of/amount of fluency (i.e., cluttering and stuttering) education and training that was being received in their programs. We believe that the information obtained from this research will assist in understanding the level of fluency disorders coursework taught to students throughout their educational careers. The study will also provide insights into fluency coursework differences that may be present between the first and second year of graduate school. We were interested in finding out whether: graduate students possess knowledge of general information about fluency disorders; the title of the instructor changes the learning outcomes of graduate students (i.e., adjunct, professor, BCS-F); 
graduate students are prepared to adequately assess and treat clients with fluency disorders.

\section{METHODS}

\section{Participants}

A total of 258 professors who taught fluency disorders coursework at ASHA accredited Communication Sciences and Disorders programs in the United States received a link to a 70-question survey (Appendix A). These professors were asked to send the online survey, via SurveyMonkey, to their respective students (freshmen through second year graduate students). Out of 258 universities who received the survey, 102 (39.53\%) universities participated with a total of 766 students completing the survey. The number of respondents was not equally distributed across the universities. Among the total respondents, 394 (51.4\%) were first year graduate students and 372 (48.6\%) were second year graduate students. Two students did not answer this demographic question (Table 1). All 50 states were represented in this survey.

\section{Survey development, validity, and reliability}

Questions in the survey were designed to expand on survey questions identified in previous studies as areas of concern in terms of academic and clinical preparation $[4,5]$. The entire survey took an average of 7 minutes to complete. For validity measures, an initial group of 30 graduate students who had previously taken a course in fluency disorders reviewed the survey for clarity, content, organization, understanding, content, wording, and comprehension of directions. An item retention criterion of $>90 \%$ agreement by judges was employed. With regard to questions and their wording, if $90 \%$ of the initial group of graduate students agreed with and understood a question and the wording, it was included in the final survey. This ensured that the questions in the survey utilized typical and familiar vocabulary that a student would have been exposed to through taking coursework in fluency disorders. Next, the revised items/questions were converted into a Likert-type scale as well as a scale with yes/no questions. Numbers 4 through 24 were yes/no and dealt with the respondents'

Table 1. Sample Size of Students According to Year in University

\begin{tabular}{ccc}
\hline & Year in University & Respondents \\
\hline Graduate & 1st Year & $51.4 \%(394 / 766)$ \\
2nd Year & $48.6 \%(372 / 766)$ \\
\hline
\end{tabular}

personal experience with regard to fluency in terms of knowing someone who stutters, coursework, assessment, treatment, and knowledge of special interest groups, fluency specialists, support groups, and their desire to learn more information about fluency. Numbers 25 through 39 were based on a Likert-type scale with answer choices of strongly agree, agree, undecided, disagree, and strongly disagree. The nature of this subset of questions explored the respondent's knowledge of the possible reasons that stuttering occurs, the intellect of a person who stutters, how the respondent reacts to stuttering, and what they believe parents should do with regard to their child who stutters. Numbers 40-70 were also yes/ no questions that assessed the respondent's knowledge with regard to identifying dysfluencies, analyzing dysfluencies, treatment of the disorder, and comfort levels with the assessment and treatment of stuttering and cluttering (Appendix A). This Likert-type scale as well as the yes/no choices were then added to the final instrument that was completed by 766 respondents. The number of respondents was not equally distributed across the universities.

The item analysis for internal consistency was conducted based on yes/no questions. Therefore, questions 4, 6, 7, 8, 9, $11,12,13,14$, and 47 were removed because they were knowledge question rather than questions about opinions. Questions 15 and 16 contained a missing value and were removed as well. As a result, when those questions were removed, 39 internally reliable items from the questionnaire remained with a Cronbach's alpha 0.891 demonstrating high internal consistency. The survey included 24 questions that elicited demographic and background information, 15 Likert-type questions, and 31 yes/no questions (Appendix A). The 24 demographic and background questions covered: amount of course time dedicated to fluency disorders, details about the instructor of the course (i.e., adjunct, professor, BCS-F), and experience of the speech-language pathology student in assessing and/or treating a person with a fluency disorder. Other questions pertained to the student's knowledge of: ASHA's Special Interest Group in Fluency Disorders, BCS-F, and common fluency groups (Appendix A).

The remaining 46-questions in the scale were divided into 15 Likert-like, 5-point scale questions, and 31 yes/no questions (Appendix A). The Likert-type points used were: strongly agree, agree, undecided, disagree, and strongly disagree. These questions included items related to causes of stuttering, spontaneous recovery, psychological aspects of stuttering, intelligence, direct and indirect therapy, genetics, parental in- 
volvement, and level of comfort when speaking to a person who stutters. The 31 yes/no questions included items related to: general fluency knowledge and terminology, fluency treatments, cluttering versus stuttering, fluency resources for speech-language pathologists and clients, and personal level of comfort in assessing and treating cluttering and stuttering. Due to limited responses from undergraduate freshmen, sophomores, and juniors, we focused on the data from first and second year graduate students. Not all participants responded to each item; therefore, the number of participants varied for each question.

\section{Statistical analysis}

Results of the survey were extracted and analyzed with Statistical Package for the Social Sciences (SPSS) software. In particular, Chi-Square tests were used to compare first year and second year graduate students. Cronbach's alpha was used to measure internal consistency.

\section{RESULTS}

\section{General Information about Stuttering Exposure to Fluency Disorders Coursework}

\section{Is there a lack of exposure to fluency disorders in the current required curriculum?}

Of students who responded, 15 of $766(2.0 \%)$ indicated that fluency coursework was not offered at the graduate level, while 493 of 766 (64.4\%) students reported that fluency disorders coursework was offered in the first year of graduate school and 329 of 766 (43.0\%) students reported that fluency disorders coursework was offered in the second year of graduate school. Of students who responded, 232 first year graduate students out of 369 (62.87\%) took a course in fluency disorders and 309 second year graduate students out of 343 (90.08) students took a course in fluency disorders. The statistical analysis shows a significant difference between first year and second year graduate students when taking a course in fluency disorders with the Chi-Square test statistic $=70.663$, $p<0.05$. Of students who responded, 89 of 733 (12.1\%) reported that an entire graduate course dedicated to fluency disorders was not offered (Table 2).

\section{Do graduate students possess knowledge of general information concerning fluency disorders?}

More than half of the respondents (64\%) indicated inappropriate knowledge on the incidence of stuttering. Moreover, there was no statistical difference in the responses between first year graduate students $(63.5 \%, 235 / 370)$ and second year graduate students $(65.8 \%, 229 / 348)(p>0.05)$. From the total, 377 of 764 (49.3\%) disagreed that when a child first begins to stutter, speech-language pathologists should not treat initially because the child may spontaneously recover. Additionally, there was no statistical difference in the responses between first year graduate students (190 of 393, 48.3\%) and second year graduate students (187 of 371, 50.4\%). From the respondents, $56 \%$ of graduate students disagreed that parents should tell children who stutter to take a breath before speaking. There was no statistical difference between responses from first year graduate students 217 of 392 (55.4\%) and second year graduate students 212 of 370 (57.3\%) on whether parents should tell children who stutter to take a breath before speaking, with the Chi-Square test statistic $=0.2177, p>0.05$. From the total, $59.1 \%$ of first and second year graduate students disagreed that speech-language pathologists should begin with direct therapy as soon as the child begins to stutter. Out of the first year graduate students, 212 of 393 (53.9\%) disagreed that speech-language pathologists should begin with direct therapy as soon as the child begins to stutter, while 239 of 370 (64.6\%) second year graduate students disagreed. There was a significant difference between first and second year graduate student responses, with the Chi-Square test statistic $=8.5088$, $p<0.05$. From those who responded, $47.6 \%$ of first and second

Table 2. Fluency Coursework Available

\begin{tabular}{|c|c|c|}
\hline Question & Response options & 1st and 2nd year Graduate Students' Responses \\
\hline \multirow{2}{*}{$\begin{array}{l}\text { 10. Is fluency coursework offered in your graduate } \\
\text { program? }\end{array}$} & Yes & $97.4 \%(746 / 766)$ \\
\hline & No & $2.0 \%(15 / 766)$ \\
\hline \multirow{2}{*}{$\begin{array}{l}\text { 11. If fluency coursework is offered in your graduate } \\
\text { program, when is it offered? }\end{array}$} & Offered in First Year & $64.4 \%(493 / 766)$ \\
\hline & Offered in Second Year & $43.0 \%(329 / 766)$ \\
\hline \multirow{2}{*}{$\begin{array}{l}\text { 13. If offered in the graduate program, is the entire } \\
\text { graduate course dedicated to fluency disorders? }\end{array}$} & Yes & $87.5 \%(641 / 733)$ \\
\hline & No & $12.1 \%(89 / 733)$ \\
\hline
\end{tabular}


year graduate students disagreed that parents should tell children who stutter to speak slower to reduce stuttering. Out of those who responded 190 of 392 (48.5\%) first year graduate students and 173 of 370 (46.8\%) second year graduate students disagreed that parents should tell children who stutter to speak slower to reduce stuttering. There was no significant difference between first and second year graduate student responses with the Chi-Square test statistic $=0.16042, p>0.05$. From the total respondents, $68.3 \%$ of first and second year graduate students did not know the latest genetic research in stuttering. Moreover, 276 of 370 (74.6\%) first year graduate students and 214 of 347 (61.7\%) second year graduate students did not know the latest genetic research in stuttering. There was a significant difference between first year and second year graduate student responses with the Chi-Squared test statistic $=13.231, p<0.05$ (Table 3 ).

\section{Are graduate students aware of popular resources for clients with fluency disorders?}

Responses to the question about knowledge of ASHA's Special Interest Group (SIG4) in fluency disorders indicated that 33\% of all students, with 159 of 393 (40.5\%) first year graduate students and 93 of 369 (25.2\%) second year graduate students had never heard of the SIG4. The Chi-Squared test revealed that there was a significant difference between first year and second year graduate student responses with the Chi-Squared test statistic $=19.325, p<0.05$. Responses to the question about knowledge of BCS-F indicated that $48.3 \%$ of both first and second year graduate students had not heard of BCS-F. In total, 201 of $393(51.1 \%)$ first year graduate students and 167 of 369 (45.3\%) and second year graduate students had not heard of BCS-F. Of all students who responded, $72.6 \%$ of both first and second year graduate students did not know how to contact a BCS-F. Of these, 288 of 390 (73.8\%) first year graduate students and 260 of $365(71.2 \%)$ second year graduate students did not know how to contact a BCS-F (Table 4). It is important to note that the survey sought to specifically look at those individuals who were taught by a Board Certified Specialist in Fluency (BCS-F). This is an ASHA-approved Specialty Certification Program that is awarded to speech-language pathologists who have met specific advanced training in this specific area. Individuals with this title (BCS-F) have demonstrated indepth knowledge of the nature and treatment of stuttering and other fluency disorders, and have undergone peer review of their qualifications.

\section{Assessment}

Are graduate students prepared to adequately assess clients with fluency disorders?

A total of $53 \%$ of both first and second year graduate students

Table 3. General Information Concerning Fluency Disorders

\begin{tabular}{|c|c|c|c|}
\hline Question & Response options & 1st year graduate students & 2nd year graduate students \\
\hline \multirow{3}{*}{$\begin{array}{l}\text { 27. When a child first begins to stutter, speech-language pathologists } \\
\text { should not treat initially because the child may spontaneously } \\
\text { recover. }\end{array}$} & Agree & $28.2 \%(111 / 393)$ & $28.3 \%(105 / 371)$ \\
\hline & Undecided & $23.4 \%(92 / 393)$ & $38.7 \%(142 / 371)$ \\
\hline & Disagree & $48.3 \%(190 / 393)$ & $50.4 \%(187 / 371)$ \\
\hline \multirow{3}{*}{$\begin{array}{l}\text { 29. Parents should tell children who stutter to take a breath before } \\
\text { speaking. }\end{array}$} & Agree & $24.7 \%(97 / 392)$ & $24.7 \%(92 / 370)$ \\
\hline & Undecided & $19.9 \%(78 / 392)$ & $17.8 \%(66 / 370)$ \\
\hline & Disagree & $55.4 \%(217 / 392)$ & $57.3 \%(212 / 370)$ \\
\hline \multirow{3}{*}{$\begin{array}{l}\text { 33. SLPs should begin with direct therapy as soon as a child begins to } \\
\text { stutter. }\end{array}$} & Agree & $18.6 \%(73 / 393)$ & $14.9 \%(55 / 370)$ \\
\hline & Undecided & $27.5 \%(108 / 393)$ & $20.5 \%(76 / 370)$ \\
\hline & Disagree & $53.9 \%(212 / 393)$ & $64.6 \%(239 / 370)$ \\
\hline \multirow{3}{*}{$\begin{array}{l}\text { 34. Parents should tell children who stutter to speak slower to reduce } \\
\text { stuttering. }\end{array}$} & Agree & $35.0 \%(137 / 392)$ & $39.2 \%(145 / 370)$ \\
\hline & Undecided & $16.6 \%(65 / 392)$ & $14.1 \%(52 / 370)$ \\
\hline & Disagree & $48.5 \%(190 / 392)$ & $46.8 \%(173 / 370)$ \\
\hline \multirow[t]{2}{*}{ 47. What is the incidence of stuttering in the general population? } & Correct \% (1\%) & $36.5 \%(135 / 370)$ & $34.2 \%(119 / 348)$ \\
\hline & Incorrect \% (>1\%) & $63.5 \%(235 / 370)$ & $65.8 \%(229 / 348)$ \\
\hline \multirow[t]{2}{*}{ 55. Do you know about the latest genetic research on stuttering? } & Yes & $25.4 \%(94 / 370)$ & $38.3 \%(133 / 347)$ \\
\hline & No & $74.6 \%(276 / 370)$ & $61.7 \%(214 / 347)$ \\
\hline
\end{tabular}


Table 4. Awareness of Popular Resources

\begin{tabular}{|c|c|c|c|}
\hline Question & Response options & 1st year graduate students & 2nd year graduate students \\
\hline \multirow{2}{*}{$\begin{array}{l}\text { 17. Have you heard of ASHA's Special Interest Group in Fluency } \\
\text { Disorders? }\end{array}$} & Yes & $59.5 \%(234 / 393)$ & $74.8 \%(276 / 369)$ \\
\hline & No & $40.5 \%(159 / 393)$ & $25.2 \%(93 / 369)$ \\
\hline \multirow[t]{2}{*}{ 18. Have you heard about Board Certified Fluency Specialists? } & Yes & $48.9 \%(192 / 393)$ & $54.7 \%(202 / 369)$ \\
\hline & No & $51.1 \%(201 / 393)$ & $45.3 \%(167 / 369)$ \\
\hline \multirow[t]{2}{*}{ 19. Do you know how to contact a Board Certified Fluency Specialists? } & Yes & $26.2 \%(102 / 390)$ & $28.8 \%(105 / 365)$ \\
\hline & No & $73.8 \%(288 / 390)$ & $71.2 \%(260 / 365)$ \\
\hline \multirow[t]{2}{*}{ 20. Have you heard of the National Stuttering Association? } & Yes & $88.8 \%(347 / 391)$ & $97.6 \%(359 / 368)$ \\
\hline & No & $11.3 \%(44 / 391)$ & $2.4 \%(9 / 368)$ \\
\hline \multirow[t]{2}{*}{ 22. Have you heard of the Stuttering Foundation of America? } & Yes & $72.5 \%(284 / 392)$ & $84.1 \%(312 / 371)$ \\
\hline & No & $27.6 \%(108 / 392)$ & $15.9 \%(59 / 371)$ \\
\hline
\end{tabular}

never completed an assessment of a client with a fluency disorder. Furthermore, 268 of the 391 (68.5\%) first year graduate students and 135 of 370 (36.5\%) of second year graduate students never completed an assessment of a client with a fluency disorder. Of all participants who responded, $12.8 \%$ of both first and second year undergraduate students agreed that they could not identify the core behaviors of stuttering. Additionally, 76 of 369 (20.6\%) first year graduate students, and 16 of 347 (4.6\%) second year graduate students agreed that they could not identify the core behaviors of stuttering. There was a significant difference between first year and second year graduate student responses with the Chi-Squared test statistic $=39.392, p<0.05$. When asked if those who responded could analyze a speech sample to determine different types of disfluencies, $15.2 \%$ of both first and second year graduate students responded that they did not know how to analyze a speech sample. Of these, 86 of 370 (23.2\%) first year graduate students and 23 of 347 (6.6\%) second year graduate students responded that they did not know how to analyze a speech sample. The Chi-Squared test showed a significant difference between the first year and second year graduate students with test statistic 37.068 and $p<0.05$.

When asked if those who responded could identify the difference between stuttering and normal disfluencies, $8.4 \%$ of both first and second year graduate students responded that they did not know how to identify the difference between stuttering and normal disfluencies. Of these, 50 of 369 (13.6\%) first year graduate students and 10 of 346 (2.9\%) second year graduate students responded that they did not know how to identify the difference between stuttering and normal disfluencies. There was a significant difference between first year and sec- ond year graduate student responses with the Chi-Squared test statistic $=25.027, p<0.05$.

Knowledge about stuttering attitudinal assessment scales increased with higher levels of education. Of students who responded, the following did not know about stuttering attitude scales: $23.9 \%$ of both first and second year graduate students, 116 of 369 (31.4\%) first year graduate students, and 55 of 346 (15.9\%) second year graduate students. There was a significant difference between first year and second year graduate student responses with the Chi-Squared test statistic $=22.853$, $p<0.05$. With regard to the Stuttering Severity Instrument 4 (SSI-4), of students who responded, $34.1 \%$ of both first and second year graduate students did not know how to score the scale. Moreover, 167 of 368 (45.4\%) first year graduate students and 77 of 347 (22.3\%) second year graduate students did not know how to score the scale. There was a significant difference between first year and second year graduate student responses with the Chi-Squared test statistic $=41.7$, $p<0.05$.

When asked if respondents would feel comfortable assessing clients who clutter after completing fluency coursework, of students who responded, $57.5 \%$ of both first and second year graduate students reported they would not feel comfortable. Of these, 137 of 232 (59.1\%) first year graduate students and 176 of 312 (56.4\%) second year graduate students reported they would not feel comfortable. There was a significant difference between first year graduate students and second year graduate students. When each group was considered, 131/232 (56.5\%) first year graduate students and 148/309 (47.9\%) second year graduate students indicated that they would not feel comfortable assessing clients who clutter, 
where the Z-test for first year graduate students had a test statistic 2.757 , and $p=$ value 0.003 , whereas the Z-test for second graduate students had a test statistic 2.264 , and $p=$ value 0.012 . When asked if those who responded would feel comfortable assessing clients who stutter after completing fluency coursework, 44 of 235 (18.7\%) first year graduate students and 36 of $312(11.5 \%)$ second year graduate students reported they would not feel comfortable. There was a significant difference between first year and second year graduate student responses $(p<0.05)$. When each group was considered, the statistical analysis showed that less than $50 \%$ of first year graduate students and second year graduate students did not feel comfortable assessing clients who stutter (Table 5).

\section{Treatment}

Are graduate students prepared to adequately treat clients with fluency disorders?

Of graduate students who responded, $49.5 \%$ had never treated clients with fluency disorders. Of these, 265 of 391 (67.8\%) first year graduate students and 113 of 372 (30.4\%) second year graduate students had never treated clients with fluency disorders. Concerning the ability to differentiate between indirect and direct therapy approaches for children who stutter, $22.2 \%$ of both first and second year graduate students who responded were unable to differentiate between indirect and direct therapy approaches. Furthermore, 110 of 368 (29.9\%) first year graduate students and 48 of 345 (13.9\%) second year graduate students who responded were unable to differentiate between indirect and direct therapy approaches. There was a significant difference between first year and second year graduate student responses with the Chi-Squared test statistic $=25.235, p<0.05$.

Concerning the ability to differentiate between stuttering modification and fluency shaping therapy, $28.9 \%$ of both first and second year graduate students who responded were unable to differentiate between the two. Of these, 142 of 370

Table 5. Assessment in Fluency Disorders

\begin{tabular}{|c|c|c|c|}
\hline Question & Response options & 1st year graduate students & 2nd year graduate students \\
\hline \multirow[t]{2}{*}{ 15. Have you ever assessed clients who have fluency disorders? } & Yes & $31.5 \%(123 / 391)$ & $63.5 \%(235 / 370)$ \\
\hline & No & $68.5 \%(268 / 391)$ & $36.5 \%(135 / 370)$ \\
\hline \multirow[t]{2}{*}{ 41. Do you know about attitude scales to assess stuttering? } & Yes & $68.6 \%(253 / 369)$ & $84.1 \%(291 / 346)$ \\
\hline & No & $31.4 \%(116 / 369)$ & $15.9 \%(55 / 346)$ \\
\hline \multirow{2}{*}{$\begin{array}{l}\text { 42. Can you analyze a speech sample to determine different types of } \\
\text { disfluencies? }\end{array}$} & Yes & $76.8 \%(284 / 370)$ & $93.4 \%(342 / 347)$ \\
\hline & No & $23.2 \%(86 / 370)$ & $6.6 \%(23 / 347)$ \\
\hline \multirow[t]{2}{*}{ 43. Do you know how to administer a reading adaptation task? } & Yes & $26.3 \%(97 / 369)$ & $45.4 \%(157 / 346)$ \\
\hline & No & $73.7 \%(272 / 369)$ & $54.6 \%(189 / 346)$ \\
\hline \multirow[t]{2}{*}{ 46. Can you identify the core behaviors of stuttering? } & Yes & $79.4 \%(293 / 369)$ & $95.4 \%(331 / 347)$ \\
\hline & No & $20.6 \%(76 / 369)$ & $4.6 \%(16 / 347)$ \\
\hline \multirow{2}{*}{$\begin{array}{l}\text { 48. Can you identify the difference between stuttering and normal } \\
\text { disfluencies? }\end{array}$} & Yes & $86.5 \%(319 / 369)$ & $97.1 \%(336 / 346)$ \\
\hline & No & $13.6 \%(50 / 369)$ & $2.9 \%(10 / 346)$ \\
\hline \multirow[t]{2}{*}{ 49. Do you know how to score the Stuttering Severity Instrument? } & Yes & $54.6 \%(201 / 368)$ & $77.8 \%(270 / 347)$ \\
\hline & No & $45.4 \%(167 / 368)$ & $22.3 \%(77 / 347)$ \\
\hline \multirow{2}{*}{$\begin{array}{l}\text { 63. After completing coursework in Fluency Disorders, do you believe } \\
\text { that you have adequate knowledge about cluttering assessment? }\end{array}$} & Yes & $43.5 \%(101 / 232)$ & $52.1 \%(161 / 309)$ \\
\hline & No & $56.5 \%(131 / 232)$ & $47.9 \%(148 / 309)$ \\
\hline \multirow{2}{*}{$\begin{array}{l}\text { 64. After completing coursework in Fluency Disorders, do you feel } \\
\text { comfortable assessing clients who clutter? }\end{array}$} & Yes & $40.9 \%(95 / 232)$ & $43.6 \%(136 / 312)$ \\
\hline & No & $59.1 \%(137 / 232)$ & $56.4 \%(176 / 312)$ \\
\hline \multirow{2}{*}{$\begin{array}{l}\text { 67. After completing coursework in Fluency Disorders, do you believe } \\
\text { that you have adequate knowledge about stuttering assessment? }\end{array}$} & Yes & $85.4 \%(199 / 233)$ & $93.6 \%(291 / 314)$ \\
\hline & No & $14.6 \%(34 / 233)$ & $7.3 \%(23 / 314)$ \\
\hline \multirow{2}{*}{$\begin{array}{l}\text { 68. After completing coursework in Fluency Disorders, do you feel } \\
\text { comfortable assessing clients who stutter? }\end{array}$} & Yes & $81.3 \%(191 / 235)$ & $88.5 \%(276 / 312)$ \\
\hline & No & $18.7 \%(44 / 235)$ & $11.5 \%(36 / 312)$ \\
\hline
\end{tabular}


(38.4\%) first year graduate students and 65 of 347 (18.7\%) second year graduate students who responded were unable to differentiate between the two. There was a significant difference between first year and second year graduate student responses with the Chi-Squared test statistic $=32.707, p<0.05$.

With regard to teaching stuttering modification techniques, among those who responded, $31.1 \%$ of both first and second year graduate students reported that they were unable to teach stuttering modification techniques. Additionally, 160 of 369 (43.4\%) first year graduate students and 63 of 347 (18.2\%) second year graduate students reported that they were unable to teach stuttering modification techniques. There was a significant difference between first year and second year graduate student responses with the Chi-Squared test statistic $=51.808, p<0.05$. Regarding teaching cancellations during stuttering modification therapy, among those who responded, $42 \%$ of both first and second year graduate students reported that they were unable to teach cancellations. Moreover, 190 of 369 (51.5\%) first year graduate students and 109 of 343 (31.8\%) second year graduate students reported that they were unable to teach cancellations. There was a significant difference between first year and second year graduate student responses with the Chi-Squared test statistic $=27.553 p<0.05$. Regarding teaching pullouts during stuttering modification therapy, among those who responded, $36 \%$ of both first and second year graduate students reported that they were unable to teach pullouts. Of these, 167 of 370 (45.1\%) first year graduate students and 87 of 344 (25.3\%) second year graduate students reported that they were unable to teach pullouts. There was a significant difference between first year and second year graduate student responses with the Chi-Squared test statistic $=29.77, p<0.05$.

When asked if those who responded would feel comfortable treating clients who clutter after completing fluency coursework, $64.1 \%$ of both first and second year graduate students reported they would not be comfortable. There was no significant difference between first year graduate students and second year graduate students, with the Chi-Square test statistic $=0.85131, p>0.05$. When asked if those who responded would feel comfortable treating clients who stutter after completing fluency coursework, $17.5 \%$ of both first and second year graduate students reported they would not be comfortable. Of these, 46 of 235 (19.6\%) first year graduate students and 50 of 315 (15.9\%) second year graduate students reported they would not be comfortable. There was no significant difference between the first year and second year graduate stu- dents, with the Chi-Square test statistic $=1.0358, p>0.05$.

With regard to other potential treatment options, among those who responded, $47.1 \%$ of both first and second year graduate students agreed that they were unaware of intervention techniques to address bullying. Of students who responded, $26 \%$ of both first and second year graduate students had never heard of response contingency programs (e.g., The Lidcombe Program). Of these, 118 of 369 (32.0\%) first year graduate students and 67 of 343 (19.5\%) second year graduate students had never heard of response contingency programs (e.g., The Lidcombe Program). There was a significant difference between first year and second year graduate student responses with the Chi-Squared test statistic $=13.675, p<0.05$.

From the total, $18.7 \%$ of both first and second year graduate students responded that they did not know about electronic devices to improve fluency (e.g., Speech Easy, etc.). Of these, the following students responded that they did not know about electronic devices to improve fluency (e.g., Speech Easy, etc.): $18.7 \%$ of both first and second year graduate students, with 85 of 369 (23.0\%) first year graduate students and 48 of $343(14.0 \%)$ second year graduate students. There was a significant difference between first year and second year graduate student responses with the Chi-Squared test statistic $=8.9796, p<0.05$. Regarding knowledge of the long-term effects of assistive devices, among those who responded (e.g., Speech Easy, etc.), about $50 \%$ of both first and second year graduate students were unaware of the long-term effects of these devices (Table 6). Of these, 203 of 369 (55.0\%) first year graduate students and 154 of 344 (44.8\%) second year graduate students were unaware of the long-term effects of these devices (Table 6). There was a significant difference between first year and second year graduate student responses with the Chi-Squared test statistic $=7.0719, p<0.05$.

\section{Impact of Instructor}

\section{Comfort levels in assessing and treating fluency disorders:} Comparing courses taught by Board Certified Specialist in Fluency vs. Non-specialists

After completing coursework in fluency disorders, of those who responded, $6.2 \%$ of both first and second year graduate students taught by a BCS-F did not feel comfortable assessing clients who stutter, while only $10.2 \%$ of first and second year graduate students taught by a BCS-F did not feel comfortable treating clients who stutter (Table 7). Out of these, only 8 of $109(7.3 \%)$ first year graduate students and 4 of 84 (4.6\%) second year graduate students taught by a BCS-F did not feel 
Table 6. Treatment in Fluency Disorders

\begin{tabular}{|c|c|c|c|}
\hline Question & Response options & 1st year graduate students & 2nd year graduate students \\
\hline \multirow[t]{2}{*}{ 16. Have you ever treated clients who have fluency disorders? } & Yes & $32.2 \%(126 / 391)$ & $69.6 \%(259 / 372)$ \\
\hline & No & $67.8 \%(265 / 391)$ & $30.4 \%(113 / 372)$ \\
\hline \multirow[t]{2}{*}{ 44. Do you know about intervention techniques to address bullying? } & Yes & $50.0 \%(184 / 368)$ & $55.9 \%(194 / 347)$ \\
\hline & No & $50.0 \%(184 / 368)$ & $44.1 \%(153 / 347)$ \\
\hline \multirow{2}{*}{$\begin{array}{l}\text { 50. Can you differentiate between the two main approaches (fluency } \\
\text { shaping and stuttering modification) to stuttering therapy? }\end{array}$} & Yes & $61.6 \%(228 / 370)$ & $81.3 \%(282 / 347)$ \\
\hline & No & $38.4 \%(142 / 370)$ & $18.7 \%(65 / 347)$ \\
\hline \multirow[t]{2}{*}{ 52. Do you know how to teach stuttering modification techniques? } & Yes & $56.6 \%(209 / 369)$ & $81.8 \%(284 / 347)$ \\
\hline & No & $43.4 \%(160 / 369)$ & $18.2 \%(63 / 347)$ \\
\hline \multirow[t]{2}{*}{ 53. Can you differentiate between indirect and direct therapy? } & Yes & $70.1 \%(258 / 368)$ & $86.1 \%(297 / 345)$ \\
\hline & No & $29.9 \%(110 / 368)$ & $13.9 \%(48 / 345)$ \\
\hline \multirow{2}{*}{$\begin{array}{l}\text { 56. Do you know how to teach cancellations when conducting } \\
\text { stuttering modification therapy? }\end{array}$} & Yes & $48.5 \%(179 / 369)$ & $68.2 \%(234 / 343)$ \\
\hline & No & $51.5 \%(190 / 369)$ & $31.8 \%(109 / 343)$ \\
\hline \multirow{2}{*}{$\begin{array}{l}\text { 57. Do you know how to teach pull-outs when conducting stuttering } \\
\text { modification therapy? }\end{array}$} & Yes & $54.9 \%(203 / 370)$ & $74.7 \%(257 / 344)$ \\
\hline & No & $45.1 \%(167 / 370)$ & $25.3 \%(87 / 344)$ \\
\hline \multirow{2}{*}{$\begin{array}{l}\text { 58. Have you heard of the Lidcombe Program for treating childhood } \\
\text { stuttering? }\end{array}$} & Yes & $68.0 \%(251 / 369)$ & $80.5 \%(276 / 343)$ \\
\hline & No & $32.0 \%(118 / 369)$ & $19.5 \%(67 / 343)$ \\
\hline \multirow[t]{2}{*}{ 59. Have you heard about the Speech Easy device to treat stuttering? } & Yes & $77.0 \%(284 / 369)$ & $86.0 \%(295 / 343)$ \\
\hline & No & $23 \%(85 / 369)$ & $14 \%(48 / 343)$ \\
\hline \multirow{2}{*}{$\begin{array}{l}\text { 60. Do you know about the long-term effects of assistive devices } \\
\text { (Speech Easy, etc.) to treat stuttering? }\end{array}$} & Yes & $45.0 \%$ (166/369) & $55.2 \%(190 / 344)$ \\
\hline & No & $55.0 \%(203 / 369)$ & $44.8 \%(154 / 344)$ \\
\hline \multirow{2}{*}{$\begin{array}{l}\text { 65. After completing coursework in Fluency Disorders, do you believe } \\
\text { that you have adequate knowledge about cluttering treatment? }\end{array}$} & Yes & $31.0 \%(71 / 229)$ & $41.7 \%(130 / 312)$ \\
\hline & No & $69.0 \%(158 / 229)$ & $58.3 \%(182 / 312)$ \\
\hline \multirow{2}{*}{$\begin{array}{l}\text { 66. After completing coursework in Fluency Disorders, do you feel } \\
\text { comfortable treating clients who clutter? }\end{array}$} & Yes & $33.5 \%(77 / 230)$ & $37.7 \%(118 / 313)$ \\
\hline & No & $66.5 \%(153 / 230)$ & $62.3 \%(195 / 313)$ \\
\hline \multirow{2}{*}{$\begin{array}{l}\text { 69. After completing coursework in Fluency Disorders, do you believe } \\
\text { that you have adequate knowledge about stuttering treatment? }\end{array}$} & Yes & $85.4 \%(199 / 233)$ & $90.2 \%(285 / 316)$ \\
\hline & No & $14.6 \%(34 / 233)$ & $9.8 \%(31 / 316)$ \\
\hline \multirow{2}{*}{$\begin{array}{l}\text { 70. After completing coursework in Fluency Disorders, do you feel } \\
\text { comfortable treating clients who stutter? }\end{array}$} & Yes & $80.4 \%(189 / 235)$ & $84.1 \%(265 / 315)$ \\
\hline & No & $19.6 \%(46 / 235)$ & $15.9 \%(50 / 315)$ \\
\hline
\end{tabular}

comfortable assessing clients who stutter, while only 9 of 109 (8.3\%) first year graduate students and 11 of 87 (12.6\%) second year graduate students taught by a BCS-F did not feel comfortable treating clients who stutter (Table 7). When students instructed by a professor or adjunct who was not board certified were asked the same question, of those who responded, $15.9 \%$ of both first and second year graduate students did not feel comfortable assessing, while 19\% of both first and second year graduate students did not feel comfortable treating clients who stutter (Table 7). Of these, 39 of 191 (20.4\%) first year graduate students and 35 of 274 (12.8\%) sec- ond year graduate students did not feel comfortable assessing, while 43 of 192 (22.4\%) first year graduate students and 46 of 277 (16.6\%) second year graduate students did not feel comfortable treating clients who stutter (Table 7).

\section{Learning outcomes of graduate students: Comparing courses taught by Board Certified Specialist in Fluency vs. Non-specialists}

Concerning graduate fluency disorders coursework, 190 of $766(24.8 \%)$ responding students reported that their graduate fluency disorders coursework was taught by a BCS-F, while 
Table 7. Graduate Students Comfort Compared by Instructor

\begin{tabular}{|c|c|c|c|c|c|}
\hline \multirow[b]{2}{*}{ Question } & \multirow[b]{2}{*}{$\begin{array}{l}\text { Response } \\
\text { options }\end{array}$} & \multicolumn{2}{|c|}{ 1st year graduate students } & \multicolumn{2}{|c|}{ 2nd Year Graduate Students } \\
\hline & & $\begin{array}{l}\text { Taught by Fluency } \\
\text { Specialist }\end{array}$ & $\begin{array}{c}\text { Taught by a professor } \\
\text { or adjunct who was not } \\
\text { board certified }\end{array}$ & $\begin{array}{c}\text { Taught by Fluency } \\
\text { Specialist }\end{array}$ & $\begin{array}{c}\text { Taught by a professor } \\
\text { or adjunct who was not } \\
\text { board certified }\end{array}$ \\
\hline \multirow{2}{*}{$\begin{array}{l}\text { 68. After completing coursework in } \\
\text { Fluency Disorders, do you feel } \\
\text { comfortable assessing clients who } \\
\text { stutter? }\end{array}$} & Yes & $92.66 \%(101 / 109)$ & $79.6 \%(152 / 191)$ & $95.4 \%(83 / 87)$ & $87.2 \%(239 / 274)$ \\
\hline & No & $7.3 \%(8 / 109)$ & $20.4 \%(39 / 191)$ & $4.6 \%(4 / 84)$ & $12.8 \%(35 / 274)$ \\
\hline \multirow{2}{*}{$\begin{array}{l}\text { 70. After completing coursework in } \\
\text { Fluency Disorders, do you feel } \\
\text { comfortable treating clients who } \\
\text { stutter? }\end{array}$} & Yes & $91.74 \%(100 / 109)$ & $77.6 \%(149 / 192)$ & $87.4 \%(76 / 87)$ & $83.4 \%(231 / 277)$ \\
\hline & No & $8.3 \%(9 / 109)$ & $22.4 \%(43 / 192)$ & $12.6 \%(11 / 87)$ & $16.6 \%(46 / 277)$ \\
\hline
\end{tabular}

Table 8. Fluency Coursework Instructor

\begin{tabular}{llc}
\hline Question & \multicolumn{1}{c}{ Response options } & Responses \\
\hline 14. Is your graduate fluency coursework taught by ... & Board Certified Fluency Specialist & $24.8 \%(190 / 766)$ \\
& Professor & $54.8 \%(420 / 766)$ \\
& Adjunct & $2.1 \%(16 / 766)$ \\
\hline
\end{tabular}

420 of 766 (54.8\%) of responding students reported being taught by a professor who did not specialize in in fluency disorders and 16 of 766 (2.1\%) students reported being taught by an adjunct who did not specialize in fluency disorders (Table 8). Data were compared between graduate students who were taught fluency coursework by a BCS-F and graduate students who were taught fluency coursework by a professor or adjunct who did not specialize in fluency disorders. Of students who responded, $15 \%$ of both first and second year graduate students taught by a BCS-F were unable to recognize the onset characteristics of stuttering. Of these, 22 of 126 (17.5\%) first year graduate students and 12 of 95 (12.6\%) second year graduate students taught by a BCS-F were unable to recognize the onset characteristics of stuttering. There was no significance difference between first year graduate students and second year graduate students (the Chi-Squared test statistic is $0.63466, p>0.05$ ).

When asked if respondents could differentiate between the two main approaches - fluency shaping and stuttering modification, of students who responded, $16.2 \%$ of both first and second year graduate students taught by a BCS-F responded that they could not differentiate between the two approaches, whereas $31.4 \%$ of both first and second year graduate students taught by a professor or adjunct who did not specialize in fluency disorders, responded that they could not differentiate between the two approaches. Of these, 20 of 126 (15.9\%) first year graduate students and 16 of 96 (16.7\%) second year graduate students taught by a BCS-F responded that they could not differentiate between the two approaches, whereas 137 of 318 (43.0\%) first year graduate students and 59 of 306 (19.3\%) second year graduate students taught by a professor or adjunct who did not specialize in fluency disorders, responded that they could not differentiate between the two approaches. When asked if respondents knew how to teach stuttering modification techniques, of students who responded, 18.5\% of both first and second year graduate students taught by a BCS-F responded that they did not know how to teach stuttering modification techniques, while $33.5 \%$ of both first and second year graduate students taught by a professor or adjunct who did not specialize in fluency disorders responded that they did not know how to teach stuttering modification techniques. Of these, 29 of 126 (23.0\%) first year graduate students and 12 of 96 (12.5\%) second year graduate students taught by a BCS-F responded that they did not know how to teach stuttering modification techniques, 152 of 317 (48.0\%) first year graduate students and 57 of 306 (18.6\%) second year graduate students taught by a professor or adjunct who did not specialize in fluency disorders, responded that they did not know how to teach stuttering modification techniques. When each group of students is considered, the statistical analysis showed that there was a significant difference between first year graduate students taught by a BCS-F and first 
Table 9. Impact of Fluency Coursework Instructor

\begin{tabular}{|c|c|c|c|c|c|}
\hline \multirow[b]{2}{*}{ Question } & \multirow[b]{2}{*}{$\begin{array}{l}\text { Response } \\
\text { options }\end{array}$} & \multicolumn{2}{|c|}{ 1st Year Graduate Students } & \multicolumn{2}{|c|}{ 2nd Year Graduate Students } \\
\hline & & $\begin{array}{l}\text { Taught by a Fluency } \\
\text { Specialist }\end{array}$ & $\begin{array}{l}\text { Taught by a professor } \\
\text { or adjunct who was } \\
\text { not specialized }\end{array}$ & $\begin{array}{l}\text { Taught by a Fluency } \\
\text { Specialist }\end{array}$ & $\begin{array}{c}\text { Taught by a professor } \\
\text { or adjunct who was } \\
\text { not specialized }\end{array}$ \\
\hline \multirow{2}{*}{$\begin{array}{l}\text { 40. Do you know how to accurately identify } \\
\text { the onset characteristics of stuttering? }\end{array}$} & Yes & $82.54 \%(104 / 126)$ & $54.4 \%(183 / 318)$ & $87.37 \%(83 / 95)$ & $85.20 \%(259 / 304)$ \\
\hline & No & $17.5 \%(22 / 126)$ & $42.5 \%(135 / 318)$ & $12.6 \%(12 / 95)$ & $14.8 \%(45 / 304)$ \\
\hline \multirow{2}{*}{$\begin{array}{l}\text { 50. Can you differentiate between the two } \\
\text { main approaches (fluency shaping and } \\
\text { stuttering modification) to stuttering } \\
\text { therapy? }\end{array}$} & Yes & $84.13 \%(106 / 126)$ & $56.92 \%(181 / 318)$ & $83.3 \%(80 / 96)$ & $80.7 \%(247 / 306)$ \\
\hline & No & $15.9 \%(20 / 126)$ & $43.0 \%(137 / 318)$ & $16.7 \%(16 / 96)$ & $19.3 \%(59 / 306)$ \\
\hline \multirow{2}{*}{$\begin{array}{l}\text { 52. Do you know how to teach stuttering } \\
\text { modification techniques? }\end{array}$} & Yes & $76.98 \%(97 / 126)$ & $52.1 \%(163 / 317)$ & $87.50 \%(84 / 96)$ & $81.4 \%(249 / 306)$ \\
\hline & No & $23.0 \%(29 / 126)$ & $48.0 \%(152 / 317)$ & $12.5 \%(12 / 96)$ & $18.6 \%(57 / 306)$ \\
\hline \multirow{2}{*}{$\begin{array}{l}\text { 56. Do you know how to teach cancellations } \\
\text { when conducting stuttering } \\
\text { modification therapy? }\end{array}$} & Yes & $75.40 \%(95 / 126)$ & $45.11 \%(134 / 317)$ & $76.04 \%(73 / 96)$ & $66.67 \%(202 / 303)$ \\
\hline & No & $24.6 \%(31 / 126)$ & $54.9 \%(174 / 317)$ & $34.4 \%(33 / 96)$ & $33.3 \%(101 / 303)$ \\
\hline \multirow{2}{*}{$\begin{array}{l}\text { 57. Do you know how to teach pull-outs } \\
\text { when conducting stuttering } \\
\text { modification therapy? }\end{array}$} & Yes & $81.8 \%(103 / 126)$ & $51.57 \%(164 / 318)$ & $81.05 \%(77 / 95)$ & $73.68 \%(224 / 304)$ \\
\hline & No & $18.3 \%(23 / 126)$ & $48.4 \%(154 / 318)$ & $19.0 \%(18 / 95)$ & $26.3 \%(80 / 304)$ \\
\hline
\end{tabular}

year graduate students taught by a professor or an adjunct, but there was no significant difference between second year graduate students taught by a BCS-F and second year graduate students taught by a professor or an adjunct (Table 9).

When asked if respondents knew how to teach cancellations when conducting stuttering modification therapy, of students who responded, $28.8 \%$ of both first and second year graduate students taught by a BCS-F responded that they did not know how to teach cancellations. Moreover, 31 of 126 (24.6\%) first year graduate students and 33 of 96 (34.4\%) second year graduate students taught by a BCS-F responded that they did not know how to teach cancellations. The ChiSquared test showed no difference between two groups with test statistic 2.019 and $p=$ value 0.1491 , while 174 of 317 (54.9\%) first year graduate students and 101 of 303 (33.3\%) second year graduate students taught by a professor or adjunct who did not specialize in fluency disorders did not know how to teach cancellations. The Chi-Squared test showed a difference between two groups with test statistic 28.3 and $p=$ value 0 .

When asked if respondents knew how to teach pullouts when conducting stuttering modification therapy, of students who responded, $18.6 \%$ of both first and second year graduate students taught by a BCS-F responded that they did not know how to teach pullouts. Of these, 23 of 126 (18.3\%) first year graduate students and 18 of 95 (19.0\%) second year graduate students taught by a BCS-F responded that they did not know how to teach pullouts. The Chi-Squared test showed no difference between two groups with test statistic 0 and $p=$ value 1 ; 154 of 318 (48.4\%) first year graduate students and 80 of 304 (26.3\%) second year graduate students taught by a professor or adjunct who did not specialize in fluency disorders, did not know how to teach pullouts. The Chi-Squared test showed a difference between two groups with test statistic 34.446 and $p=$ value 0 (Table 9 ).

\section{DISCUSSION}

It appears from the results of this study that many graduate students are lacking the knowledge and exposure they need to adequately assess and treat fluency disorders. Tellis et al. [4], Yaruss and Quesal [5], and Yaruss et al. [1] expressed similar concerns that minimal coursework and lack of experience in assessing and treating fluency disorders at the university level is a significant issue. Brisk et al. [3] reiterated that practicing school-based speech-language pathologists continue to harbor doubts about treating fluency disorders, as only half of the respondents in their study believed they could develop appropriate goals to treat children with fluency disorders. Brisk et al. [3] believed that this inadequacy stemmed from the lack of education, knowledge, and experience at the college level.

We compared the two groups (first and second year gradu- 
ate level students) to further explore if we could capture where changes in learning, knowledge, comfort, and other aspects were actually occurring. Learning the differences between the two groups could lead universities to perhaps change their order of curriculum to have the fluency course be earlier in the graduate program. Since the university is where most academic coursework and training is initially covered, it should be the place where students are first exposed to this information. Our results, however, indicate that $30.4 \%$ of graduate students are completing their education having never treated fluency clients. Many students do not have the opportunity to treat fluency disorders during their practicum because fluency clients represent such a small portion of the overall population of clients, which further compounds the problem of the existence of limited academic information pertaining to fluency disorders. These students, therefore, are not adequately equipped with the appropriate tools to assess and treat fluency disorders once they graduate and join the workforce.

Results of this study indicate that a majority of graduate students did not know the incidence of stuttering or about genetic research in stuttering. Most students did not how to contact a BCS-F. Even after completing coursework, a majority of students also did not feel comfortable assessing and treating clients who clutter and believed that they did not have adequate knowledge of cluttering. Regardless of whether or not graduate students were taught by a BCS-F, a majority did not know the difference between fluency shaping and stuttering modification, how to administer the Stuttering Severity Instrument (SSI-4), or about the long-term effects of using assistive devices (e.g., speech easy). We recognize a limitation of our current study was that we only asked about BCS$\mathrm{F}$ and not other instructors who have expertise in this area. There are faculty experts in Fluency Disorders who have not undertaken the process to become board certified; however, these individuals still specialize in Fluency Disorders.

The differences between the two groups were meaningful as they gave us an insight into what year (first or second of graduate school) information about stuttering was being imparted and learned. The data from first year graduate students indicated that roughly half did not know about the long-term effects of assistive devices (e.g., speech-easy) and were unaware of intervention techniques to address bullying. Most of these first year graduate students had never completed an assessment of fluency disorders and had never treated a client with a fluency disorder. With regard to cluttering, even after completing coursework in fluency disorders, a majority of these students did not believe that they had adequate knowledge of cluttering assessment. Second year graduate students showed a slight improvement when compared to first year graduate students; however, a large proportion of second year graduate students also followed similar trends as the first year graduate students. By and large, as second year graduate students advanced through their education, their knowledge and comfort levels with fluency disorders increased.

Some students, however, are still uninformed about certain fundamental aspects about fluency disorders. From the data, 97 of 392 (24.7\%) first year graduate students and 92 of 370 (24.9\%) second year graduate students believed that parents should tell their children with fluency disorders to take a breath before speaking. There is no significant difference between first year and second graduate students with ChiSquare test statistic 0 and $p=$ value 1 . When asked about whether children should be told to reduce the rate of speech (slow down) to improve fluency, 137 of 392 (34.9\%) responding first year graduate students and 145 of 370 (39.2\%) responding second year graduate students agreed. There is no significant difference between first year and second graduate students with Chi-Square test statistic 1.292 and $p=$ value 0.2557 . These two aspects (parents telling the child to take a breath before speaking and asking children to reduce their rates of speech) are not typically recommended by experts in fluency disorders [18]. For clarification, there is a difference between parents asking children to slow down and clinicians teaching techniques that alter some aspect of speaking rate. of the initial syllable of each utterance, which changes rate.

To compound the issues discussed previously, one potential problem is that master's level students can now graduate with zero hours specifically dedicated to fluency disorders. The argument that fluency disorders is not as prevalent as other disorders (e.g., articulation) is valid; however, with the advances of today's technology, a system could be created in which students could review evaluation and treatment sessions by visiting a secure website and observing BCS-F as they demonstrate evidence-based evaluation and treatment techniques for fluency disorders. Steyl et al. [19] found that graduate students who completed a course in experiential learning had a significant increase in comfort levels when working with people with fluency disorders. Students could, therefore, view several assessment and treatment techniques that they can apply to their future clients. This type of approach would help ensure that even if the students do not receive first-hand 
experience in assessing and/or treating these lower-incidence disorders, they still could satisfy ASHA's requirements of being competent in assessing and treating disorders under the speech-language pathology scope of practice.

While it is encouraging to note that most $(87.5 \%$; 641/733) graduate students stated they had an entire graduate course dedicated to fluency disorders, the majority of students in this study expressed a desire to learn more about fluency disorders. One solution would be for faculty members to incorporate a hands-on approach to teaching fluency disorders coursework. This study demonstrated that more hands-on training should be the focus of classroom instruction. If graduate student clinicians explicitly practice therapy techniques, participate in workshops, and increase their overall exposure to stuttering and cluttering, they will then improve their knowledge and skills in assessing and treating fluency disorders. The new hands-on lab component of the ASHA convention could also be a way for practical training to take place. Henri [20] also provided suggestions for improving graduate coursework in fluency disorders via inter-university collaboration with exposure to clients from several universities.

Another avenue for faculty who teach fluency disorders courses to consider is to attend workshops that are specifically designed to train faculty members in the nature and treatment of fluency disorders. For example, the Stuttering Foundation of America sponsors a free, 4-day workshop (conference fees and lodging costs, a per diem for meals) taught by experts in fluency disorders, with the purpose of helping faculty members share, edit, and expand their existing course content; develop new content and materials; choose appropriate readings; develop learning activities; and provide assignments. An interesting feature of the course is that online modules are developed for each content area so that materials are accessible to participants before and after the course. Naturally, faculty should also explore other avenues and sources (e.g., National Stuttering Association workshops, ASHA workshops, etc.) to enhance their coursework and to receive alternate viewpoints and philosophies of assessment and treatment of fluency disorders. These resources will enable faculty to return to their classes with current information about assessment and treatment of fluency disorders, affording students to opportunity increase their knowledge in this area.

There are several barriers to achieving appropriate graduate education and training in fluency disorders. These barriers include: limited caseloads of clients with fluency disorders, ASHA requirements concerning graduate clinical hours, less overall classroom time dedicated to fluency disorders, inadequate knowledge about fluency disorders, and lower comfort levels with fluency disorders. While these issues pose a challenge to providing adequate exposure to fluency disorders for graduate students, there are many alternative options to consider that would allow students to gain exposure to coursework and training in fluency disorders. These include access to online assessment and treatment sessions conducted by BCS-F or other faculty with expertise in Fluency Disorders, inter-university collaboration, professional practice seminars, and engaging in independent research. If many of these suggestions can be incorporated into university academic and training programs, perhaps this will encourage these students to attend fluency workshops and join a special interest group (e.g., Fluency Disorders) after they graduate and join the workforce $[2,21]$. The knowledge and awareness obtained through workshops or special interest groups could result in an increase of the quality of treatment that persons with fluency disorders receive. Myths in the area of fluency and fluency disorders are still perpetuated; therefore, the results of this study will also help current faculty understand and meet their students where they are currently in the learning process.

Although there are limitations within the area of fluency disorders coursework, resources highlighted throughout this paper can be used to provide optimal and improved academic and clinical training in fluency disorders. If students and faculty proactively seek ways to further their knowledge about fluency disorders, more students will enter the profession with adequate knowledge and confidence to effectively assess and treat fluency disorders.

\section{ACKNOWLEDGMENTS}

\section{Andrea Jensen}

Andrea Jensen earned her Bachelor of Science degree in Communication Sciences and Disorders from Geneva College in Beaver Falls, PA as well as her Master of Science degree in Speech-Language Pathology from Misericordia University in Dallas, PA. She was on the Dean's List and has completed research and data analysis for this study.

\section{Abriel McCann}

Abriel McCann is a recent graduate and researcher in the Speech-Language Pathology Department at Misericordia University. She was on the Dean's List and was President of Misericordia's NSSLHA chapter. She has completed research 
and data collection for this study. She has presented research at state, national, and international conferences.

\section{Amanda Tomaselli}

Amanda Tomaselli is a certified Speech-Language Pathologist who graduated from the Speech-Language Pathology Program at Misericordia University in Dallas, PA. While attending Misericordia University, she was on the Dean's List and conducted numerous research studies which she presented at state, national, and international conferences. Amanda has completed research and data collection for this study.

\section{Denis Anson, M.S., OTR}

Denis Anson is the Director of Research and Development in the Assistive Technology Research Institute at Misericordia University. He has analyzed data for this study.

\section{REFERENCES}

1. Yaruss S, Lee J, Kikani K, Leslie P, Herring C, Ramachandar S, et al. Update on didactic and clinical education in fluency disorders: 2013-2014. Am J Speech Lang Pathol. 2017;26:124-137.

2. Sommers RK, Caruso AJ. Inservice training in speech-language pathology: Are we meeting the needs for fluency training? Am J Speech Lang Pathol. 1995 Aug; 4:22-28.

3. Brisk DJ, Healey EC, Hux KA. Clinicians' training and confidence associated with treating school-age children who stutter: A national survey. Lang Speech Hear Serv Sch. 1997;28:164-176.

4. Tellis GM, Bressler L, Emerick K. An exploration of clinicians' views about assessment and treating of stuttering. Perspect Fluen Fluen Disord. 2008;18:16-23.

5. Yaruss SJ, Quesal RW. Academic and clinical education in fluency disorders: An update. J Fluency Disord. 2002;27:43-63.

6. Ainsworth S. The specialist in the treatment for stuttering. J Fluency Disord. 1974;1:48-52.
7. Kelly EM, Martin JS, Baker KE, Rivera NI, Bishop JE, Krizizke CB, et al. Academic and clinical preparation and practices of school speech-language pathologists with people who stutter. Lang Speech Hear Serv Sch. 1997;28:195-212.

8. Mallard AR, Gardner LS, Downey CS. Clinical training in stuttering for school clinicians. J Fluency Disord. 1988;13:253-259.

9. Yaruss SJ. Current status of academic and clinical education in fluency disorders at ASHA-accredited training programs. J Fluency Disord. 1999;24:169-183.

10. Betz I, Blood G, Blood, I. University students' perceptions of preschool and kindergarten children who stutter. J Commun Disord. 2008;41:259-273.

11. Cooper E, Cooper C. Clinician attitudes toward stuttering: A decade of change (1973-1983). J Fluency Disord. 1985;10:19-33.

12. Lass NJ, St. Louis KO. A survey of communicative disorders students' attitudes toward stuttering. J Fluency Disord. 1981;6:49-79.

13. Lass NJ, Ruscello DM, Pannbacker MD, Schmitt JF, Everly-Myers DS. Speech-language pathologists' perceptions of child and adult female and male stutterers. J Fluency Disord. 1989;14:127-134.

14. Leahy MM. Attempting to ameliorate student therapists' negative stereotype of the stutterer. Eur J Disord Commun. 1994;29:39-49.

15. Ragsdale JD, Ashby J.K. Speech-language pathologists' connotations of stuttering. J Speech Lang Hear Res. 1982;25:75-80.

16. Woods CL, Williams DE. Traits attributed to stuttering and normally fluent males. J Speech Hear Res. 1976;19:267-278.

17. Yairi E, Williams DE. Speech clinicians' stereotypes of elementaryschool boys who stutter. J Commun Disord. 1970;3:161-170.

18. Guitar, B. Stuttering: An integrated approach to its nature and treatment (3rd ed.). Lippincott Williams \& Wilkins; 2013.

19. Steyl NA, Klein JF, Howell ML, Dalton JC. Increasing knowledge and skills of graduate students in a fluency disorders course. Contemp Issues Commun Sci Disord. 2016;43:164-173.

20. Henri BP. Graduate students preparation: Tomorrow's challenge. ASHA. 1994;36:43-46.

21. Crichton-Smith I, Wright J, Stackhouse J. Attitudes of speech and language therapists towards stammering: 1985 and 2000. Int J Lang Commun Disord. 2003;38:213-234. 


\section{APPENDIX}

\section{Appendix A. Survey Questionnaire}

1. University name

2. State of college/university

3. Which of the following best describes your current status in your SLP program?

\section{Students answered the following questions with yes/no:}

4. Do you know someone who stutters?

5. Is fluency coursework offered in your undergraduate program?

6. If fluency coursework is offered in your undergraduate program, when is it offered?

7. If offered in the undergraduate program, is the entire undergraduate course dedicated to fluency disorders?

8. If offered in the undergraduate program, is only part of the course dedicated to fluency disorders?

9. Is your undergraduate fluency coursework taught by (Check all that apply: Board Certified Fluency Specialist, Professor, Adjunct, N/A I am a graduate student, Coursework not offered)?

10. Is fluency coursework offered in your graduate program?

11. If fluency coursework is offered in your graduate program, when is it offered?

12. If offered in the graduate program, is only part of the graduate course dedicated to fluency disorders?

13. If offered in the graduate program, is the entire graduate course dedicated to fluency disorders?

14. Is your graduate fluency coursework taught by (Check all that apply: Board Certified Fluency Specialist, Professor, Adjunct, N/A I am a graduate student, Coursework not offered)?

15. Have you ever assessed clients who have fluency disorders? If so, check all that apply.

16. Have you ever treated clients who have fluency disorders? If so, check all that apply.

17. Have you heard of ASHA's Special Interest Group in Fluency Disorders?

18. Have you heard about Board Certified Fluency Specialists?

19. Do you know how to contact a Board Certified Fluency Specialists?

20. Have you heard of the National Stuttering Association?

21. Have you heard of the Stuttering Home Page?

22. Have you heard of the Stuttering Foundation of America?

23. Do you know how to contact support groups for persons who stutter?

24. Would you like to learn more information about stuttering?

\section{Students answered the following statements with strongly agree, agree, undecided, disagree, strongly disagree:}

25. Stuttering is caused because a person talks faster than he or she can think.

26. Many children who stutter do not become fluent because they do not try hard enough.

27. When a child first begins to stutter, SLPs should not treat initially because the child may spontaneously recover.

28. Children who stutter get lower test scores than children who do not stutter.

29. Parents should tell children who stutter to take a breath before speaking.

30. Stuttering is caused by psychological problems.

31. SLPs should treat children who stutter as soon as disfluencies are noticed.

32. Persons who stutter are less intelligent than persons who do not stutter.

33. SLPs should begin with direct therapy as soon as a child begins to stutter.

34. Parents should tell children who stutter to speak slower to reduce stuttering. 
35. Parents should tell children who stutter to think before they speak.

36. Stuttering is hereditary.

37. Stuttering is caused because of problems with brain functioning.

38. When talking to a person who stutters, I do not know how to react.

39. When speaking to someone who stutters, I feel: uncomfortable; sympathetic; helpless; awkward; calm; scared; anxious; fine.

\section{Students answered the following questions with yes/no:}

40. Do you know how to accurately identify the onset characteristics of stuttering?

41. Do you know about attitude scales to assess stuttering?

42. Can you analyze a speech sample to determine different types of disfluencies?

43. Do you know how to administer a reading adaptation task?

44. Do you know about intervention techniques to address bullying?

45. Can you identify associated motor behaviors (stuttering secondaries)?

46. Can you identify the core behaviors of stuttering?

47. What is the incidence of stuttering in the general population?

48. Can you identify the difference between stuttering and normal disfluencies?

49. Do you know how to score the Stuttering Severity Instrument?

50. Can you differentiate between the two main approaches (fluency shaping and stuttering modification) to stuttering therapy?

51. Do you know how to tally disfluencies?

52. Do you know how to teach stuttering modification techniques?

53. Can you differentiate between indirect and direct therapy?

54. Do you know about Silverman's Three Wishes Task?

55. Do you know about the latest genetic research on stuttering?

56. Do you know how to teach cancellations when conducting stuttering modification therapy?

57. Do you know how to teach pull-outs when conducting stuttering modification therapy?

58. Have you heard of the Lidcombe Program for treating childhood stuttering?

59. Have you heard about the Speech Easy device to treat stuttering?

60. Do you know about the long-term effects of assistive devices (Speech Easy, etc.) to treat stuttering?

61. Have you heard about the disorder of cluttering?

62. Do you know the difference between stuttering and cluttering?

63. After completing coursework in Fluency Disorders, do you believe that you have adequate knowledge about cluttering assessment?

64. After completing coursework in Fluency Disorders, do you feel comfortable assessing clients who clutter?

65. After completing coursework in Fluency Disorders, do you believe that you have adequate knowledge about cluttering treatment?

66. After completing coursework in Fluency Disorders, do you feel comfortable treating clients who clutter?

67. After completing coursework in Fluency Disorders, do you believe that you have adequate knowledge about stuttering assessment?

68. After completing coursework in Fluency Disorders, do you feel comfortable assessing clients who stutter?

69. After completing coursework in Fluency Disorders, do you believe that you have adequate knowledge about stuttering treatment?

70. After completing coursework in Fluency Disorders, do you feel comfortable treating clients who stutter? 